NAK cũng phu thuộc vào sư khác nhau về nguyên lý đo. NAK không tiếp xúc (phụt hơi) dựa trên sự đè dẹt của giác mạc trung tâm do luồng hơi phát ra từ đầu đo, diển tích đè dẹt cố định có đường kính 3,06 mm rất giống với nguyên lý đo của NAK Goldmann. Cũng chính vì lý do này giá trị đo của NAK Goldmann và NAK không tiếp xúc khá tương đồng nhau ở các miền NA.

\section{KẾT LUÂ̂N}

Trị số NA đo được với NAK Maclakov tương đối khác biệt với NAK Goldmann, NAK không tiếp xúc và sự khác biệt này phụ thuộc miền NA. Trong thực hành lâm sàng cần lưu ý đến sự khác biệt này và không nên ngoại suy giá trị của NAK này cho NAK kia theo ngoại suy tuyến tính.
TÀI LIÊU THAM KHẢO

1. Đố Như Hơn (2014). Nhãn khoa tập 2, NXB Y hoc, $238-251$.

2. Nguyê̂n Thị Thanh Thu (2002). Nghiên cứu NA trung bình của một nhóm người Việt Nam trưởng thành bằng NAK Goldmann. Luận văn tốt nghiệp thạc sỹ y học, Đại học Y Hà Nội, Hà Nội.

3. Ayres Mdos S (1968). Comparative study between the Goldmann and Maclakov tonometers. Rev Bras Oftalmol, 27(1), 57-68.

4. Võ Đức Dũng, Trân Thị Phương Thu (2005). So sánh kết quả NA đo bằng NAK Goldmann và NAK Maclakov.Y Hoc TP. Hồ Chí Minh, tập 9 phụ bản của Số 1, 55-59.

5. Pham Minh Đức, Đoàn Trong Hâu (2003), So sánh kết quả NA đo bằng NAK khổng tiếp xúc và Maclakov ở người Viêt Nam bình thường trên 20 tuổi, tạp chí Y Học TP. Hồ Chí Minh,tập 7 Phụ bản số 1.

\title{
ĐÁNH GIÁ HIỂU QUẢ PHƯƠNG PHÁP TIÊM NONG KHỚP DƯỚI DSA ĐIỀU TRI BỆNH ĐÔNG CỨNG KHỚP VAI BẰNG THANG ĐIỂM SPADI
}

\author{
Trần Anh Tuấn ${ }^{1}$, Nguyễn Thị Thu Hằng ${ }^{1}$, Nguyễn Duy Trinh ${ }^{1}$
}

\section{TÓM TĂT}

Mục tiêu nghiên cứu: Nghiên cứu hiệu quả điều trị bơm nong khớp vai dưới DSA bằng thang điểm SPADI và các yếu tố ảnh hưởng. Đối tượng và phương pháp: Các bênh nhân đông cứng khớp vai được bơm nong ổ khớp dưới DSA, dựa trên lượng thuốc bơm, mức độ ngấm các buồng khớp để đánh giá mức đố hep và lương thuốc cần thiêt để nong khớp, đánh giá mức độ cải thiện triệu chứng lâm sàng. Kết quả: Có 38 khớp vai được bớm nong, trong đó các buống hẹp chính là buồng dưới $(84,2 \%)$, rãnh nhị đầu $(94,7 \%)$. Mức độ hẹp nặng và trung bình lần lượt 34,2\% và 52,6\%. Các buồng được nong đạt tỷ lệ cao tữ $77,8 \%$ tói $100 \%$ (buông trển). Thang điểm SPADI giảm 20,03 $\pm 7,81$ điểm sau 2 tuân và $32,47 \pm 10,80$ sau 4 tuần. Tuổi trẻ và điều trị sớm là hai yếu tố cho kết quả tiên lượng điều trị tốt hơn. Kết luâan: Bớm nong ổ khớp điều trị bệnh đông cứng khớp vai dưới DSA là an toàn và đạt hiệu quản cao, thang điểm SPADI dễ áp dụng đánh giá hiệu quả điều trị.

Tư khóa: Đông cứng khớp vai, ȘPADI, bơm nong.

\section{SUMMARY}

EVALUATION THE EFFECTIVENESS OF FLUOROSCOPIC-GUIDED HYDRODILATATION IN THE TREATMENT OF FROZEN SHOULDER BASED ON SPADI SCORES

\footnotetext{
${ }^{1}$ Trung tâm điên quang, BV Bach Mai Chịu trách nhiệm chính: Trần Anh Tuấn Email: Bs.trananhtuan@yahoo.com.vn Ngày nhận bài: 21.12.2020 Ngày phản biện khoa học: 25.01.2021 Ngày duyệt bài: 2.2.2021
}

Objective: This study was conduted to evaluate
the effectiveness of fluoroscopic-guided hydrodilatation in the treatment of frozen shoulder based on Shoulder Pain and Disability Index (SPADI) scores and other factors. Material and method: The patients diagnosed with frozen sholder disease were hydrodilatated with corticosteroid injection performed via an anterior approach under fluoroscopy. Based on the amount of drug pumped, the degree of drug infiltration, we could evaluate the stenosis grade and calculate the medication volume exactly needed for each procedure in combination with level of clinical symptom improvement. Patients were characterized at admission and followed up at at two and four weeks post-intervention with Shoulder Pain and Disability Index (SPADI) scores and measurement of motion active and passive range. Result: A total of 38 consecutive patients with frozen shoulder underwent a distension arthrogram mostly in inferior chamber $(84.2 \%)$ and bicipital sulcus (94.7\%). The mild and severe stenosis were conscutively $34.2 \%$ and $52.6 \%$. The good results post-dilatation ranged from $77.8 \%$ to $100 \%$ (superior chamber). The SPADI score was reduced to $20,03 \pm 7,81$ and $32,47 \pm 10,80$, consecutively, after 2 and 4 weeks post-distension. Coclusion: Our study results consolidated that arthrographic capsular distension progressing is an effective treatment for adhesive capsulitis. This procedure was performed through an anterior-lateral approach under fluoroscopic guidance is accurate, reliable and minimally invasive.

Keywords: adhesive capsulitis, arthographic capsular distension, SPADI

\section{I. ĐĂT VẤN ĐỀ}

Tiêm nong khớp vai dưới hướng dẫn của máy 
DSA điều trị bệnh đông cứng khớp vai (ĐCKV) là kỹ thuật giúp xác định vị trí, theo dõi động hình ảnh dòng thuốc đi vào ổ khớp, nong giãn dần các buồng khớp một cách dễ dàng và chính xác, chủ động và an toàn. Đánh giá hiệu quả điều trị bệnh lý này dựa và thang điểm SPADI (Shoulder Pain and Disability Index) là thang điểm dễ áp dụng phản ánh chính các được hiệu quả lâm sàng.

\section{II. ĐỐI TƯợNG VÀ PHƯƠNG PHÁP NGHIÊN CỨU}

\subsection{Tiêu chuẩn lựa chọn bệnh nhân ĐCKV}

- Đau khớp vai kéo dài >2 tháng

- Giảm tầm vận động thụ động và chủ động khớp vai

- Trên phim chụp ổ khớp: Một hoặc nhiều buồng khớp không ngấm hoặc khổng ngấm đây thuốc hoă̆c lượng thuốc chụp ổ khớp < $10 \mathrm{ml}$

2.2 Địa điểm, thời gian nghiên cứu: Trung tâm điện quang, bệnh viện Bạch Mai, từ 7/2017 đến 7/2020

\subsection{Phương pháp nghiên cứu}

- Cõ̃ mẫu: Lấy mẫu thuận tiện, thực tế thu được 38 bệnh nhân

- Quy trình: Thủ thuật bơm nong ổ khớp dưới hướng dẫn DSA:

+ Định vị điểm chọc kim trên da ở vị trí nối giữa $1 / 3$ dưới với $2 / 3$ trên của ổ khớp trên màn tăng sáng.

+ Khi đầu kim chạm xương, rút nhẹ kim, bơm ít thuốc cản quang để thấy thuốc lan theo khe khớp, bơm khoảng 5-10ml thuốc cản quang xenetic để tiến hành chụp ổ khớp, ghi nhận lượng thuốc chụp, mức độ hẹp buồng khớp.

+Tiến hành nong ổ khớp bằng hỗn dịch: xenetic + thuốc tê + 1ống depo-medrol 40mg + nước muối, lượng bơm $20-30 \mathrm{ml}$, vào tuỳ theo mức độ dính của khoang khớp. Dừng bớm nong khi:

1. Hỗn dịch thuốc đã làm dãn, căng đầy các buồng khớp.

2. Thuốc thoát ra ngoài ổ khớp.

3. Bệnh nhân đau, có cảm giác căng cứng vùng vai, không chịu được nữa.

Đánh giá kêt quả ngay sau bơm nong:

+ Hình thái của ổ khớp:

+ Lượng thuốc.

+ Cảm giác của người bệnh: dựa vào thang điểm SPADI

+ Tầm vân động khớp vai:

Hướng dẫn tập luyện sau bơm nong:

Đánh giá tiển triển bệnh theo thời gian: 2 tuần, 4 tuân.

Đánh giá mức độ đau và chức năng khớp vai dựa vào thang điểm SPADI. SPADI là chỉ số đánh giá mức độ đau và chức năng riêng của khớp vai. Bệnh nhân tự đánh giá mức độ đau và mức độ khó khăn của mình theo từng câu hỏi trước khi tiêm nong khớp vai và sau tiêm nong 2 tuần và 4 tuần, mổi câu hỏi sẽ có câu trả lời từ 0 - 10, tương ứng với 0 là không đau hoặc không có khó khăn, 10 là đau rất tồi tệ hoặc khó khăn đòi hỏi phải có giúp đỡ. Chỉ số SPADI được đánh giá qua 13 câu hỏi, điểm tối đa là 130 điểm sau đó được quy đổi về 100 . Điểm SPADI càng cao thì mức độ giảm chức năng của khớp vai càng nhiều.

* Mức độ đánh giá:

$<20$ : Nhe

21-50: Trung bình

51-80: Nặng

>80: Rất nặng

*Kêt quả giảm đau và phục hồi chức năng vận động

<20: Tốt

21-50: Khá

51-80: Trung bình

$>80$ : Kém

\section{KẾT QUẢ NGHIÊN CỨU}

3.1. Đặc điểm chung: Có 38 bệnh nhân, trong đó vai phải: $42,1 \%$, vai trái: $57,9 \%$. Thời gian bị bệnh trung bình $6,50 \pm 3,61$ tháng. Bệnh nhân nữ chiếm $52,4 \%$.

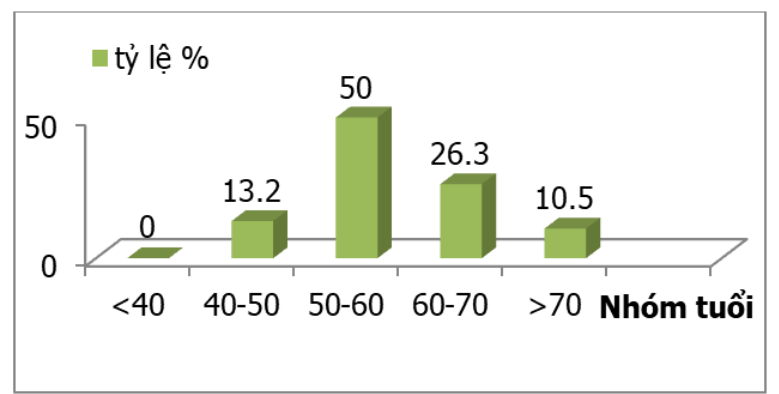

Biểu đồ 3.1: Phân bố BN theo nhóm tuổi

Nhận xét: Tuổi mắc bệnh nhiều nhất là từ 50 - 60 tuổi chiếm tỉ lệ 50\%.

3.2 Hình ảnh chụp khớp vai cản quang trước khi bơm nong: Lượng thuốc cản quang

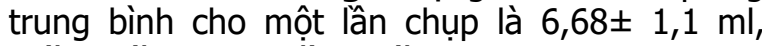
thấp nhất $4 \mathrm{ml}$, nhiều nhất $10 \mathrm{ml}$.

3.2.1 Hình ảnh chupp khớp vai cản quang:

Bảng 3.1: Hình ảnh chụp khớp vai cản quang.

\begin{tabular}{|c|c|c|}
\hline $\begin{array}{c}\text { Hình ảnh chụp khớp vai } \\
\text { cản quang }\end{array}$ & $\mathbf{n}$ & $\mathbf{\%}$ \\
\hline Hẹp buồng trên & 16 & 42,1 \\
\hline Hẹp buồng trước & 13 & 34,2 \\
\hline Hẹp buồng sau & 18 & 47,4 \\
\hline Hẹp buồng dưới & 32 & 84.2 \\
\hline Hẹp rãnh nhị đầu & 36 & 94,7 \\
\hline
\end{tabular}


Nhân xét: $94,7 \%$ các bênh nhân hẹp rãnh nhị đầu, hẹp buồng dưới chiếm $84,2 \%$, là các buồng hẹp hay gặp nhất.

3.2.2. Đánh giá mức độ hẹp theo thay đổi số buồng ngấm thuốc.

Bảng 3.2. Mức độ hẹp theo số buồng:

\begin{tabular}{|c|c|c|}
\hline Các mức độ biểu hiệ̂n & $\mathbf{n}$ & $\mathbf{\%}$ \\
\hline $\begin{array}{c}\text { Hẹp rất nặng: chí còn thầy khe } \\
\text { khớp }\end{array}$ & 1 & 2,6 \\
\hline Hẹp nặng: Hẹp 3/4 buồng & 10 & 26,3 \\
\hline Hẹp trung bình: Hẹp 2 buồng & 23 & 60,5 \\
\hline Hẹp nhẹ: Hẹp 1 buồng & 4 & 10,5 \\
\hline Tống số & $\mathbf{3 8}$ & $\mathbf{1 0 0}$ \\
\hline
\end{tabular}

Nhận xét: Tỷ lệ hẹp trung bình chiếm tỷ lệ cao nhất $60,5 \%$ và hẹp nặng chiếm tỷ lệ $26,3 \%$. Rất hẹp và hẹp nhẹ chỉ chiếm $2,6 \%$ và $10,5 \%$.

3.2.3. Đánh giá mức độ hẹp theo liều thuốc chụp.

Bảng 3.3. Mức độ hẹp theo liều thuốc chụp

Các mức độ biếu hiện

Hẹp rất nặng : 4-5ml

\begin{tabular}{|c|c|c|}
\hline Hẹp rât nặ̆ng : 4-5ml & 2 & 5,2 \\
\hline Hẹp nặng: $6 \mathrm{ml}$ & 13 & 34,2 \\
\hline Hẹp trung bình: 7-8ml & 20 & 52,6 \\
\hline Hẹp nhê: $9-10 \mathrm{ml}$ & 3 & 7,9 \\
\hline Tống số & $\mathbf{3 8}$ & $\mathbf{1 0 0}$ \\
\hline
\end{tabular}

Nhân xét: Dựa theo lượng thuốc bơm vào được khi chụp khớp giúp đánh giá mức độ hẹp của khe khớp. Tỷ lệ hẹp nặng chiếm 34,2\%, hẹp trung bình chiếm tỳ lệ cao nhất 52,6\%.

3.3. Hiệu quả điêu trị nong ổ khớp. Lượng thuốc nong được trung bình là 19,66士 $2,47 \mathrm{ml}$. Lượng thuốc bơm được ít nhất là $15 \mathrm{ml}$, cao nhất $25 \mathrm{ml}$.

\subsubsection{Các buồng khớp đã nong được:}

Bảng 3.4: Các buồng khớp đã nong được.

\begin{tabular}{|c|c|c|}
\hline $\begin{array}{c}\text { Các buồng } \\
\text { khớp bị hẹp }\end{array}$ & $\begin{array}{c}\text { Số buồng nong } \\
\text { được/buồng hẹp }\end{array}$ & $\mathbf{\%}$ \\
\hline Buống trên & $16 / 16$ & 100 \\
\hline Buồng trước & $12 / 13$ & 92,3 \\
\hline Buồng sau & $16 / 18$ & 88,8 \\
\hline Buồng dưới & $25 / 32$ & 78,1 \\
\hline Buồng nhị đầu & $28 / 36$ & 77,8 \\
\hline
\end{tabular}

Nhân xét: Trong 4 buồng khớp và ngách nhị đầu đầu khớp vai, buồng trên dễ nong nhất, đạt tỷ lệ nong được là $100 \%$, rãnh nhị đầu hiệu quả bơm nong đạt thấp nhất là $77,8 \%$, nhiều trường hợp bị rách bao khớp trước khi kịp nong rãnh nhị đầu.

\subsubsection{Số lân bơm nong:}

Bảng 3.5: Số lân bớm nong

\begin{tabular}{|c|c|c|}
\hline Số lần bơm nong & $\mathbf{N}$ & $\mathbf{\%}$ \\
\hline Nong 1 lần & 31 & 81,6 \\
\hline Nong 2 lần & 7 & 18,4 \\
\hline Tống cộng & $\mathbf{3 8}$ & $\mathbf{1 0 0}$ \\
\hline
\end{tabular}

Nhận xét: Có 31 bệnh nhân chỉ cần nong 1 lần đã cho kết quả tốt, đạt $81,6 \%$. Có 7 bệnh nhân $(18,4 \%)$ phải nong lại lần thứ 2 do tổn thương dính khớp nhiều.

3.4 Đánh giá mức độ cải thiện qua thang điểm SPADI:

3.4.1. Thay đổi chỉ Số SPADI toàn phân tại các thời điểm nghiên cứu

Bảng 3.6: Đánh giá mức độ cải thiện SPADI toàn phần:

\begin{tabular}{|c|c|c|c|}
\hline SPADI toàn phần & $\mathbf{n}$ & $\mathbf{T B} \pm$ SD & p \\
\hline $\begin{array}{c}\text { SPADI toàn phần 0 } \\
\text { (St0) }\end{array}$ & 38 & $64,74 \pm 10,80$ & \\
\hline $\begin{array}{c}\text { SPADI toàn phần } 2 \\
\text { (St2) }\end{array}$ & 38 & $44,71 \pm 11,00$ & \multirow{2}{*}{00,} \\
\cline { 1 - 3 } $\begin{array}{c}\text { SPADI toàn phần } 4 \\
\text { (St4) }\end{array}$ & 38 & $32,26 \pm 14,50$ & \\
\hline Hiệu Số St0 - St2 & 38 & $20,03 \pm 7,81$ & \\
\hline Hiệu Số St0 - St4 & 38 & $32,47 \pm 9,74$ & \\
\hline
\end{tabular}

Nhân xét: SPADI toàn phần trung bình trước nong là $64,74 \pm 10,80$ điểm, sau nong 2 tuần giảm 20,03 $\pm 7,81$ điểm, sau nong 4 tuần giảm $32,47 \pm 9,74$ điểm so với trước tiêm. Cải thiện có ý nghĩa thống kê $(p<0,001)$.

3.4.2. Đánh giá hiệu quả điều trị đau và cải thiện chức năng khớp vai theo thang điểm SPADI toàn phàn

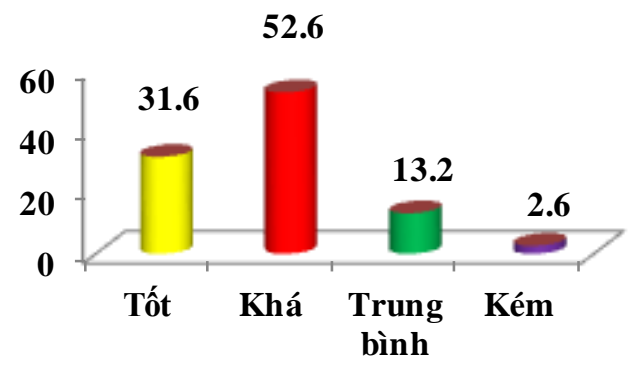

Biểu đồ 3.2. Phân loại kêt quả điều trị theo SPADI Nhân xét: Sau 4 tuần điêu trị, có $31,6 \%$ bệnh nhân đạt kết quả tốt, $52,6 \%$ bệnh nhân đạt kết quả khá và có 1 bệnh nhân, chiếm 2,6\% đạt kết quả kém.

3.5. Các yếu tố liên quan đến kết quả điêu trị

3.5.1 Mối liên quan giữa tuổi và kêt quả điều trị theo chỉ số SPADI toàn phân.

Bảng 3.7:Tuổi trung bình của bệnh nhân và kêt quả điều trị

\begin{tabular}{|c|c|c|c|c|}
\begin{tabular}{|c|c|c|} 
Kết quả \\
điêuu trị
\end{tabular} & $\mathbf{n}$ & Tuổi TB & $\begin{array}{c}\text { Min- } \\
\text { Max }\end{array}$ & \multirow{2}{*}{$\mathbf{p}$} \\
\hline Tốt & 12 & $52,42 \pm 5,93$ & $43-63$ & \\
\cline { 1 - 4 } Khá & 20 & $60,70 \pm 6,63$ & $50-72$ & \multirow{2}{*}{$<0,05$} \\
\hline TB và kém & 6 & $70,33 \pm 12,82$ & $56-91$ & \\
\cline { 1 - 4 } Tổng & 38 & $59,61 \pm 9,55$ & $43-91$ & \\
\hline
\end{tabular}


Nhận xét: Nhóm cho kết quả điều trị tốt có tuổi trung bình là 52,42 , nhóm kết quả điều trị trung bình và kém có tuổi trung bình là 70,33 . Sự khác biệt có ý nghĩa thống kê với $p<0,05$.

3.5.2 Môi liên quan giữa thời gian bi bệnh và kêt quả điêuu trị theo chỉ số SPADI toàn phân.

Bảng 3.8: Thời gian bị bệnh trung bình và kêt quả điều trị

\begin{tabular}{|c|c|c|c|c|}
\begin{tabular}{|c|c|c|} 
Kết quả \\
điêu trị
\end{tabular} & $\mathbf{n}$ & $\begin{array}{c}\text { Thời gian } \\
\text { (tháng) }\end{array}$ & $\begin{array}{c}\text { Min- } \\
\text { Max }\end{array}$ & \multirow{2}{*}{$\mathbf{p}$} \\
\hline Tốt & 12 & $4,67 \pm 2,29$ & $3-12$ & \\
\cline { 1 - 4 } Khá & 20 & $6,45 \pm 3,15$ & $3-14$ & \multirow{2}{*}{$<0,05$} \\
\hline TB và kém & 6 & $10,33 \pm 4,41$ & $6-18$ & \\
\hline Tống & 38 & $6,50 \pm 3,61$ & $3-18$ & \\
\hline
\end{tabular}

Nhận xét: thời gian bị bệnh của nhóm có hiệu quả điều trị tốt là 4,67 tháng, nhóm kết quả trung bình và kém là 10,33 . Sự khác biệt có ý nghĩ thống kê với $p<0,05$.

\section{BÀN LUẬN}

4.1. Đặc điểm chung: Nghiên cứu 38 bệnh nhân ĐCKV theo biểu đồ 3.2 cho thấy nữ: 20 BN chiếm 52,6\%, nam: 18 bệnh nhân chiếm 47,6\%, tỷ lệ nữ/nam $=1,11$, sự khác biệt không có ý nghĩa thống kê với $p>0,05$.

Theo biểu đồ 3.1, tuổi trung bình của 38 bệnh nhân ĐCKV là 59,6 , nhóm tuổi gặp nhiều nhất là nhóm 50-60 tuổi, chiếm 50\%, không có bệnh nhân nào dưới 40 tuổi, thời gian bị bệnh trung bình trước khi điều trị là 6,5 tháng, ít nhất là 3 tháng, dài nhất là 18 tháng.

Theo biểu đồ 3.3 thấy tổn thương vai phải chiếm tỷ lệ $42,1 \%$, vai trái chiếm $57.9 \%$, sự khác biệt không có ý nghĩa thống kê.

\section{2. Đặc điểm hình ảnh khớp vai}

4.2.1. Chup khớp cản quang trước tiêm nong. 38 BN trong nhóm nghiên cứu $100 \%$ các bệnh nhân đều có hẹp buông khớp, trong đó hẹp rãnh nhị đầu gặp trong $94,7 \%$ các trường hợp, hẹp buồng dưới chiếm $84,2 \%$, hẹp buồng trên $42,1 \%$, hẹp buồng sau $47,4 \%$, hẹp buồng trước ít gặp nhất chiếm 34,2\%. Như vậy dính khớp trong bệnh ĐCKV là dính không đồng nhất, có những buồng khớp dính nhiều như ngách nhị đầu và buồng dưới.

Bảng 3.2 cho thây tỷ lệ hẹp trung bình tỷ lệ cao nhất $60,5 \%$, hẹp nặng chiếm tỷ lệ $26,3 \%$. Rất hẹp và hẹp nhe chỉ chiếm tỷ lệ thấp là $2,6 \%$ và $10,5 \%$. Như vậy mức độ hẹp đánh giá theo số buồng khớp bị dính cũng phù hợp với mức độ hẹp theo lượng thuốc chụp khớp ban đầu.

Theo tác giả Thomazeau $\mathrm{H}^{(\mathbf{1})}$ trong nghiên cứu so sánh hình ảnh khớp vai trong bệnh lý đụng dập đai xoay và ĐCKV giữa trước và sau phẫu thuật, chụp khớp vai có độ nhạy $98 \%$, độ đăcc hiệu $100 \%$ trong chẩn đoán ĐCKV. Theo tác giả Carrilon $Y^{(2)}$ bình thường dung tích khớp vai khoảng $10 \mathrm{~mm}$, cấu tạo gồm 4 buồng: trên, trước, sau, dưới (ngách nhị đầu tách ra từ buồng dưới , đi xuống rãnh nhị đầu).

Theo nghiên cứu của Nguyễn Văn Sơn ${ }^{(3)}$ trên 105 BN, hẹp rãnh nhị đầu chiếm 99\%, hẹp buồng dưới chiếm $98,1 \%$, hẹp buồng sau chiếm $53,3 \%$, hẹp buồng trước chiếm 42,9\%, hẹp buồng trên chiếm $21,9 \%$. Trong đó $23,8 \%$ hẹp nặng và rất nặng khi hẹp toàn bộ $4-5$ buồng khớp, $26,7 \%$ thể hẹp trung bình, 35,2\% thể nhẹ, $14,3 \%$ thể hẹp ít.

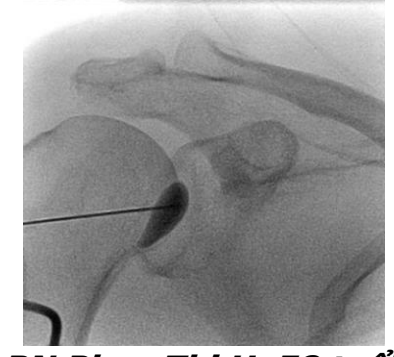

Hình 4.1: BN Phan Thi H, 58 tuổi, đau khớp vai phải 12 tháng, chụp khớp vai có hình ảnh hẹp toàn bộ các buồng khớp.

4.2.2. Lượng thuốc cản quang trung bình cho một lần chụp $(\mathrm{ml})$ và mức độ hẹp. Lượng thuốc bơm được vào khớp khi tiến hành chụp khớp vai cản quang là dấu hiệu để chẩn đoán đồng thời đánh giá mức độ nặng của bệnh, trong 38 bệnh nhân ĐCKV được chụp thì 1 : Lượng thuốc trung bình chụp khớp là $6,68 \mathrm{ml}$. Có 1 trường hợp bơm được $10 \mathrm{ml}$ nhưng vẫn được đánh giá là hẹp do buồng nhị đầu không ngấm thuốc. Theo bảng 3.3 cho thấy tỷ lệ hẹp trung bình chiếm tỷ lệ cao nhất là $52,6 \%$, hẹp nặng chiếm tỷ lệ $36,8 \%$.

\subsection{Hiệu quả tiêm nong ổ khớp}

4.3.1. Lượng hốn dịch thuốc dùng tiêm nong. Lượng thuốc trung bình $19,66 \mathrm{ml}$, ít nhất $15 \mathrm{ml}$, lớn nhất là $25 \mathrm{ml}$.

Sự giãn nở tối đa đạt được khi có sự võ̃ của bao khớp, sẽ dẫn đến sự giẫn nở lớn nhất của bao và tương ứng với sự cải thiện lâm sàng tối đa. Nhưng đa số các tác giả Tveita ${ }^{(4)}, Y{ }^{2}{ }^{(5)}$, Clement( ${ }^{(6)}$ : dùng từ 20 tới $50 \mathrm{ml}$ hỗn dịch mục đích để đạt được sự vỡ bao khớp trên màn chiếu. Sở dĩ các tác giả không thống nhất về lượng thuốc sử dụng khi bơm nong vì quan điểm không giống nhau, nếu chỉ để giảm đau, chống viêm thì không dùng nhiều thuốc, nhưng nếu để nong khớp thì phải dùng lượng cao. 


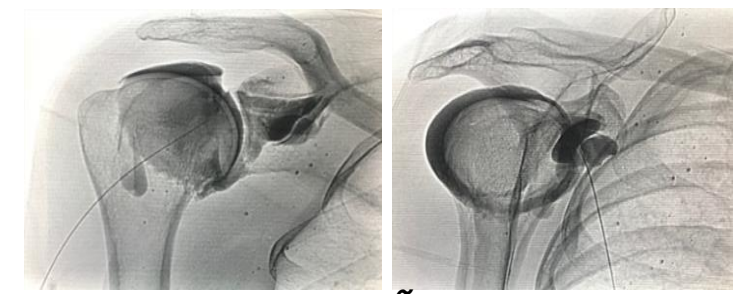

Hình 4.2. BN Nguyễn Thị Th, 50t, các

buồng khớp ngấm đầy thuốc sau nong

4.3.2. Đánh giá khả năng nong của các

buồng khớp. Trong nghiên cứu của chúng tôi theo bảng 3.4 buồng trên dễ nong nhất, đạt tỷ lệ nong được là $100 \%$, buồng trước và buồng sau cũng nong dễ dàng, đạt tỷ lệ $92,3 \%$ và $88,8 \%$. Buồng dưới khó nong hơn đạt $78,1 \%$. Đặc biệt rãnh nhị đầu, 94,7\% các bệnh nhân của chúng tôi có hẹp rãnh nhị đầu và hiệu quả bơm nong đạt thấp nhất là $77,8 \%$.

4.3.3. Đánh giá số lần nong ở nhóm nghiên cứu. Theo bảng 3.5 chúng tôi có 31 bệnh nhân chỉ cần nong 1 lần đã cho kết quả tốt, đạt $81,6 \%$. Có 7 bênh nhân $(18,4 \%)$ phải nong lại lần thứ 2 sau 1 tuần do tổn thương dính khớp nhiều, chúng tôi phải bơm với áp lực rất lớn, BN đau nhiều, chúng tôi tiến hành nong từ từ giúp bệnh nhân đỡ đau và hạn chế biến chứng rách bao khớp do bơm áp lực quá lớn, tuy nhiên những bệnh nhân này chưa bóc tách được hết các ngách, các túi cùng nên chúng tôi hẹn $\mathrm{BN}$ nong tiếp lần 2 sau 1 tuần. Sau một tuẩn dưới tác dụng chống viêm giảm đau của thuốc, bao khớp đỡ dính hơn chúng tôi nong lại lần 2 đã đạt độ giãn nở tối đa của buồng khớp.

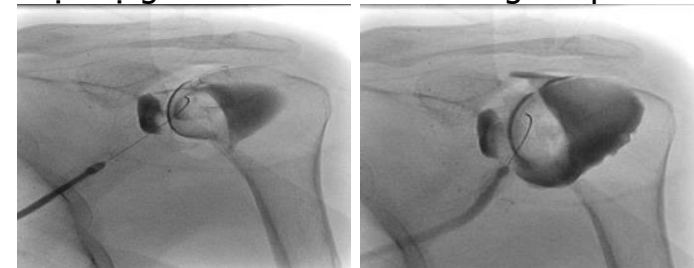

Hình 4.3: Vũ Thị H, 72 tuổi, nong lân 1, do quá dính, bơm áp lực rất nặng, bơm được

$18 \mathrm{ml}$, không bóc được ngách nhị đâu.

4.3.4. Mức độ cải thiênn chi số SPADI. Điểm SPADI toàn phần trung bình trước nong là $64,74 \pm 10,80$ điểm, sau nong 2 tuần giảm $20,03 \pm 7,81$ điểm, sau nong 4 tuần giảm $32,47 \pm 9,74$ điểm so với trước tiêm. Cải thiện có ý nghĩa thống kê $(p<0,001)$.

Tương tự kết quả nghiên cứu của tác giả Nguyễn Thị Bảo Thoa ${ }^{(7)}$ khi bơm nong ổ khớp dưới hướng dẫn của siêu âm: SPADI toàn phần trung bình trước nong là $72,32 \pm 13,95$ điểm. Sau nong 2 tuần giảm $27,05 \pm 15,73$ điểm còn
45,27 $\pm 17,4$ điểm, sau nong 4 tuần tiếp tục giảm $38,74 \pm 20,14$ điểm so với trước nong còn $33,58 \pm 21,19$ điểm.

Nghiên cứu của Tveita và cs $^{(4)}$ nghiên cứu trên 2 nhóm, 1 nhóm 37 BN tiêm khớp vai thông thường, 1 nhóm 39 BN tiêm nong khớp vai dưới hướng dẫn màn tăng sáng, điểm SPADI toàn phần trung bình trước nong là 63 điểm, sau nong 6 tuần là 26 điểm.

Kết quả thu được phân loại dựa trên thang điểm SPADI toàn phần: Sau 4 tuần điều trị, có 31,6\% bệnh nhân đạt kết quả tốt, 52,6\% bệnh nhân đat kết quả khá và có 1 bênh nhân, chiếm $2,6 \%$ đạt kết quả kém. Nguyễn Văn Sơn ${ }^{(3)}$ tiêm nong khớp vai dưới hướng dẫn của $x$ quang với kết quả chung cuộc là $87 \%$ bệnh nhân tốt, 10,5\% bênh nhân trung bình và 1,0\% bênh nhân kém. Các chỉ số đánh giá, các thang điểm của chúng tôi và tác giả Nguyến Văn Sơn khác nhau, vì thế không thể kết luận phương pháp nào tốt hơn nhưng đều khẳng định rằng tiêm nong khớp vai là một thủ thuật giúp giảm đau, cải thiện tầm vận động khớp và chức năng khớp vai như các tác già Yoon ${ }^{(5)}$, Clement ${ }^{(6)}$ trên thế giới đã chứng minh.

4.4. Bàn luận về những yếu tố ảnh hưởng đến hiệu quản bơm nong

4.4.1. Tuổi. Nhóm cho kết quả điều trị tốt có tuổi trung bình là 52,42, nhóm cho kết quả khá có tuổi trung bình 60,7 , nhóm kết quả điều trị trung bình và kém có tuổi trung bình là 70,33. Sự khác biệt có ý nghĩa thống kê với $p<0,05$, điều đó có nghĩ là tuổi càng trẻ thì hiệu quả điền trị càng tốt.

4.4.2. Thời gian bị bênh. Thời gian bị bệnh trung bình của nhóm có hiệu quả điêu trị tốt là 4,67 tháng, nhóm kết quả khá là 6,45 tháng, nhóm kết quả trung bình và kém là 10,33. Sự khác biệt có ý nghĩ thống kê với $p<0,05$, có nghĩa là thời gian bị bệnh càng dài, bệnh nhân được điều trị chậm trễ thì hiệu quả điều trị càng thấp.

\section{KẾT LUÂ̂N}

Tiêm nong khớp vai dưới DSA là phương pháp an toàn và hiệu quả, thang điểm SPADI là thang điểm dễ áp dụng trong thực hành đánh giá mức độ cải thiện của bơm nong ổ khớp.

\section{TÀI LIẸU THAM KHẢO}

1. Thomazeau H. Les voies d'abord arthroscopiques et chirurgicales de l'épaule. Revue de Chirurgie Orthopedique et Reparatrice de l'appareil moteur. 2007;93(7):25-26.

2. Carrillon $\mathbf{Y}$. Imagerie des muscles de la coiffe des rotateurs. La Lettre du rhumatologue. 2013;396:14-17. 
3. Nguyễn Văn Sơn. Nghiên cứu đăc điểm hình ảnh đông cứng khớp vai và hiệu quả điều trị bằng bơm nong ổ khớp dưới hướng dẫn của xquang. Luận án tiến sỹ y học. 2011;

4. Tveitå EḰ, Tariq R, Sesseng $S$, Juel NG, Bautz-Holter E. Hydrodilatation, corticosteroids and adhesive capsulitis: a randomized controlled trial. BMC musculoskeletal disorders. 2008;9(1):1-10.

5. Yoon JP, Chung SW, Kim J-E, et al. Intraarticular injection, subacromial injection, and hydrodilatation for primary frozen shoulder: a randomized clinical trial. Journal of shoulder and elbow surgery. 2016;25(3):376-383.

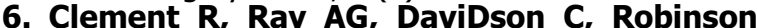
CM, PERks FJ. Frozen shoulder: long-term outcome following arthrographic distension. Acta Orthop Belg. 2013;79(4):368-7

7. Nguyễn Thi Bảo Thoa. Đánh giá hiệu quả cửa phương pháp tiêm nong khớp vai dưới hướng dân của siêu âm trong điều trị viêm quanh khớp vai thể đông cứng. Đại học y Hà nội; 2015.

\section{KẾT QUẢ BƠM XI MĂNG QUA CUỐNG ĐIỀU TRI LÚN THÂN ĐỐT SỐNG NGƯ⿱C, THẮT LƯNG DO LOÃNG XƯƠNG TẠI BỆNH VIỆN THANH NHÀN}

\section{TÓM TĂT}

Mục tiêu: Đánh giá kết quả bơm xi măng qua cuống điều trị lún thân đốt sống ngực, thắt lưng do loãng xương tại Bệnh viện Thanh Nhàn. Phương pháp: Thiết kế nghiên cứu mô tả trên 71 bệnh nhân. Kết quả: Biến chứng tràn xi măng trong mổ gồm có tỷ lệ bệnh nhân có tràn xi măng qua bờ trước thân đốt sống, có tràn vào đĩa đệm lần lượt là $16,9 \%$ và $11,3 \%$. Tỷ lệ ngấm xi măng trên $2 / 3$ đốt là $78,9 \%$. Có sự khác biệt có ý nghĩa thống kê $(p<0,001)$ giữa điểm VAS trung bình của bệnh nhân tại các thời điểm theo dõi. Tỷ lệ bệnh nhân đạt kết quả rất tốt và tốt sau bơm xi măng qua da lần lượt là $63,4 \%$ và $29,6 \%$. Kết luận: Bơm xi măng đốt sổng qua da là một phương pháp ít xâm lấn, hiệu quả điêuu trị cao với tỷ lệ biến chứng thấp và thường không để lại di chứng, giảm đau tốt và phục hồi vận động nhanh chóng. măng.

Tư khóa: Lún thẩn đổt sống, loãng xương, bơm xi

\section{SUMMARY}

THE RESULTS OF CEMENT INJECTION

THROUGH THEPEDICLE THAT TREAMENT OF

THORACO-LUMBAR VERTEBRAE COMPRESSION PATIENTS DUE TO OSTEOPOROSIS

\section{AT THANH NHAN HOSPITAL}

Objective: To evaluate the results of cement injection through the pedicle that treatment of thoracolumbar vertebrae compression patients due to

\section{${ }^{1}$ Bệnh viện Thanh Nhàn}

2Viện Chân thương Chỉnh Hinh, Bệnh viện Hưu nghi Việt Đức

${ }^{3}$ Trường Đại học Y Hà Nội

Chiu trách nhiệm chính: Nguyễn Lê Bảo Tiến

Email: bstiencsvd@gmail.com

Ngày nhận bài: 18.12.2020

Ngày phản biện khoa họ: 22.01.2021

Ngày duyệt bài: 1.2.2021
Hà Văn Lĩnh ${ }^{1}$, Nguyễn Lê Bảo Tiến ${ }^{2}$, Phan Minh Trung ${ }^{1}$, Võ Văn Thanh ${ }^{2,3}$

osteoporosis at Thanh Nhan Hospital. Methods: This is a descriptive study of 71 patients. Results: The symptoms in surgery were the percentage of patients who were $16.9 \%$ and $11.3 \%$, respectively. The percentage ofthe cement infiltration on $2 / 3$ vertebrae was $78.9 \%$. There was a statistically significant difference $(p<0.001)$ between the mean VAS score at the time. The percentage of patients with very good and good results after cement injectionthrough the skin were $63.4 \%$ and $29.6 \%$, respectively. Conclusion: The cement injection through the skin was a less invasive method, highly effective treatment with low symptom rate and this method hasn't leaved any sequelae, good pain relief, fast musculoskeletal system recovery.

Keywords: Vertebrae compression, osteoporosis, cement injection.

\section{I. ĐẶT VẤN ĐỀ}

Loãng xương là một rối loạn của hệ thống xương được đặc trưng bởi sự suy giảm sức bền của xương, dẫn tới làm tăng nguy cơ gãy xương[1]. Theo thống kê tại Mỹ có khoảng $700.000-1.000 .000$ trường hợp gãy xẹp thân đốt sống do loãng xương mỗi năm, với hơn $1 / 3$ trở thành đau mạn tính. Xẹp đốt sống xảy ra ở $25 \%$ bệnh nhân nữ trên 50 tuổi và $40 \%$ bên nhân từ $80-85$ tuổi. Do vậy xẹp đốt sống do loãng xương đang trở thành một vấn đề sức khỏe toàn câu, cần được quan tâm khi tuổi thọ của dân số thế giới ngày càng tăng lên.

Xẹp đốt sống là một trong những biến chứng "thầm lặng" ở những bệnh nhân bị loãng xương. Để điêu trị xẹp đốt sống do loãng xương thì có nhiều phương pháp. Tuy nhiên phần lớn các trường hợp xẹp đốt sống do loãng xương không đáp ứng với điều trị nội khoa, bệnh nhân vẫn có tình trạng đau lưng kéo dài, ảnh hưởng nhiều 